\title{
Maternal Exposure to Alcohol and Low Birthweight: A Systematic Review and Meta-Analysis
}

\section{Exposição maternal ao álcool e baixo peso ao nascer: revisão sistemática e metanálise}

\author{
Priscilla Perez da Silva Pereira10 Fabiana Araújo Figueiredo Da Mata ${ }^{2}$ \\ Ana Claudia Morais Godoy Figueiredo ${ }^{2}$ Roberta Borges Silva ${ }^{2}$ Maurício Gomes Pereira ${ }^{2}$ \\ ${ }^{1}$ Department of Nursing, Universidade Federal de Rondônia, Porto \\ Velho, RO, Brazil \\ 2 Department of Medicine, Universidade Brasilia, Brasília, DF, Brazil \\ Address for correspondence Priscilla Perez da Silva Pereira, PhD, \\ Departamento de Enfermagem, University Federal of Rondônia, Av. \\ Presidente Dutra, 2967, 76801-016, Olaria, Porto Velho, Ro, Brazil \\ (e-mail: priperez83@gmail.com).
}

Rev Bras Ginecol Obstet 2019;41:333-347.

\begin{abstract}
Keywords

- pregnant women

- low birthweight

- alcoholic beverages

- systematic review

- meta-analysis

Objective To investigate the relationship between maternal exposure to alcohol and low birthweight (LBW).

Methods The literature search was performed in January 2017 using the following electronic databases: Medline, Embase, LILACS, SciELO, Web of Science, Scopus, CINHAL, Proquest, and PsychInfo. The search strategy used the following terms: alcohol drinking, binge drinking, alcohol-related disorders, alcoholism, alcohol addiction/ use/abuse/consumption, light/moderate/social/low drinking, low birthweight, case-control studies, retrospective studies, and cohort studies. No restrictions regarding language or publication date were considered. The literature search yielded 2,383 articles, and after screening and eligibility assessment, 39 articles were included in the systematic review, and 38 studies were included in the meta-analysis.

Results Maternal alcohol consumption was associated with LBW among retrospective cohort studies (relative risk $[R R]=1.37 ; 95 \% \mathrm{Cl}$ [confidence interval]:1.10-1.77; $\left.\mathrm{I}^{2}=98.4 \% ; p<0.01\right)$. Prospective cohort studies $(\mathrm{RR}=1.11 ; 95 \% \mathrm{Cl}: 0.98-1.25$; $\mathrm{I}^{2}=81.5 \% ; p<0.01$ ), and case-control studies (odds ration $[\mathrm{OR}]=1.16 ; 95 \% \mathrm{Cl}$ : $\left.0.68-1.97 ; I^{2}=61.2 \% ; p=0.05\right)$ showed no association between alcohol and LBW. No publication bias was identified, and the meta-regression showed that the sample size influenced the high heterogeneity among retrospective cohort studies. The subgroup analysis showed differences in association between groups when compared by sample size, type of adjustment, or crude measures and publication year.

Conclusions We have not found an association between alcohol consumption during gestation and LBW in the analysis in all of the subgroups. In addition, we have found a high heterogeneity between the primary studies, which is related to methodological differences in the conduction of these studies.
\end{abstract}

(D) Priscilla Perez da Silva Pereira's ORCID is https://orcid.org/00000001-8900-6801.

received January 10, 2019 accepted March 21, 2019
DOI https://doi.org/ $10.1055 / \mathrm{s}-0039-1688905$. ISSN $0100-7203$.
Copyright $\odot 2019$ by Thieme Revinter Publicações Ltda, Rio de Janeiro, Brazil
License terms

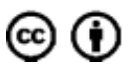




\section{Resumo}
Palavras-chave
- gestante
- baixo peso ao nascer
- consumo de álcool
- revisão sistemática
- metanálise

Objetivo Investigar a associação entre a exposição maternal ao álcool e o baixo peso ao nascer.

Método A busca na literatura ocorreu em janeiro de 2017 nas seguintes bases de dados eletrônicas: Medline, Embase, LILACS, SciELO, Web of Science, Scopus, CINHAL, Proquest, e Psychlnfo. A estratégia de busca utilizou os seguintes termos: alcohol drinking, binge drinking, alcohol-related disorders, alcoholism, alcohol addiction/use/ abuse/consumption, light/moderate/social/low drinking, low birthweight, case-control studies, retrospective studies, e cohort studies. Não houve restrição de idioma e ano de publicação. A busca na literatura identificou 2.383 artigos, e depois de analisados conforme os critério de elegibilidade, foram incluídos na revisão sistemática 39 estudos, e 38 estudos foram incluídos na metanálise.

Resultados A amostra foi composta por 497.023 gestantes. O consumo materno de álcool foi associado ao baixo peso ao nascer entre os estudos de coorte retrospectiva (risco relativo $[R R]=1,37$; IC [intervalo de confiança] 95\%: 1,10-1,77; $\left.\right|^{2}=98,4 \%$; $p<0,01$ ). Os estudos de coorte prospectiva ( $R R=1,11$; IC95\%: $0,98-1,25$; $\mathrm{I}^{2}=81,5 \% ; p<0,01$ ) e caso-controle (razão de chances [OR, na sigla em inglês] $=1,16$; IC95\%: $\left.0,68-1,97 ;\left.\right|^{2}=61,2 \% ; p=0,05\right)$ não apresentaram associação entre $o$ consumo e o desfecho. Não foi identificado viés de publicação, e a metarregressão mostrou que o tamanho da amostra influenciou a heterogeneidade entre os estudos de coorte prospectiva. Na análise por subgrupo, houve diferenças entre os grupos por tamanho de amostra, por tipo de ajuste e por ano de publicação.

Conclusão Não encontramos associação entre o consumo e o baixo peso ao nascer em todas as análises por subgrupo. Além disso, encontramos alta heterogeneidade entre os estudos primários, e isto se deve possivelmente às diferenças metodológicas na condução destes estudos.

\section{Introduction}

Alcohol consumption is becoming an increasingly common habit among women. The amount and type of consumption differ depending on social, economic, and cultural aspects. The prevalence of alcohol intake by pregnant women varies from 4.5 to $31 \%$ in countries such as the United States of America, India, and Canada. ${ }^{1,2}$

The negative effects of alcohol consumption on a fetus are mainly related to the pattern of drinking and genetic factors. The type of drink, the amount of alcohol consumed per occasion, its continuous or sporadic use, the gestational period of the woman, and both maternal and fetal abilities to metabolize alcohol influence the occurrence of adverse effects on fetal growth and development. ${ }^{3,4}$

Maternal alcohol exposure has been associated with infertility, spontaneous miscarriage, prematurity, and physical, neurological, and psychological alterations. ${ }^{5}$ The intake of one shot of an alcoholic drink per day during the pregestational period might decrease birthweight (BW) by $91 \mathrm{~g}$ on average. If this same amount is ingested over the last 3 months of pregnancy, then the BW might be decreased by $160 \mathrm{~g}^{6}{ }^{6}$

Birthweight is a widely used indicator to evaluate social, economic and environmental conditions to which pregnant women are exposed. Low birthweight (LBW) is defined by the World Health Organization (WHO) as newborns weighting $<2,500 \mathrm{~g}$, regardless of the gestational age. ${ }^{7}$
Low birthweight contributes to between $60 \%$ and $80 \%$ of neonate deaths worldwide. The global prevalence of LBW is of $15.5 \%$, and $96.5 \%$ of the cases occur in developing countries. Infants who were born with LBW have a higher risk of developing infectious diseases in their $1^{\text {st }}$ year of life. Moreover, they are more likely to develop metabolic and cognitive disorders during childhood and adolescence. ${ }^{8}$

Low birthweight is directly related to preterm birth, to intrauterine growth restriction, or to a combination of both. In turn, these events depend on maternal characteristics, such as age, race, educational level, economic conditions, genetic aspects, obstetric history, nutrition, and lifestyle. ${ }^{9,10}$

A systematic review by Patra et $\mathrm{al}^{3}$ found a risk association between maternal alcohol consumption and LBW. Henderson et $\mathrm{al}^{10,11}$ in two systematic reviews without metaanalysis, regarding moderate consumption and binge drinking, showed no consistent evidence for a risk association regarding LBW, on both consumption types.

Previous systematic reviews and primary studies indicate that there is no consensus regarding a risk association between alcohol consumption during pregnancy and LBW. The most recent systematic review published by Patra et al ${ }^{3}$ included studies performed until 2009, and did not include studies conducted in South and Central America and in Asia. Furthermore, these authors did not investigate the high heterogeneity found among the included studies. Therefore, 
we aimed to update the systematic reviews regarding the association between maternal exposure to alcohol and LBW.

\section{Methods}

The present research is registered at the International Prospective Register of Systematic Reviews (PROSPERO) under the Center for Reviews and Dissemination (CRD) number 42015023706.

\section{Eligibility Criteria}

We have included case-control, cohort studies (retrospective and prospective), and systematic reviews that evaluated the relationship of maternal exposure to alcohol and LBW (defined as $<2,500 \mathrm{~g}$ ); 1 study defined LBW as $<2,000 \mathrm{~g}$, and 1 study evaluated only consumption for very LBW $(1,500 \mathrm{~g})$.

\section{Information Sources, Search Strategy, and Study Selection}

The literature search for potential eligible studies was performed in January 2017 using the following electronic databases: Medline, Embase, LILACS, SciELO, Web of Science, Scopus, CINHAL, Proquest, and PsychInfo. No restrictions regarding language or publication date were considered.

The search strategy primarily applied for Medline (via PubMed) was alcohol drinking (Mesh) OR alcohol drinking (TIAB) OR binge drinking (TIAB) OR alcohol-related disorders (Mesh) OR alcohol-related disorders (TIAB) OR alcoholism (TIAB) OR alcohol addiction (TIAB) OR alcohol use (TIAB) OR light drinking (TIAB) OR moderate drinking (TIAB) OR social drinking (TIAB) OR low drinking (TIAB) OR alcohol abuse (TIAB) OR alcohol consumption (TIAB) AND infant, low birthweight (Mesh) OR low birthweight (TIAB) OR birthweight (TIAB) AND case-control studies (Mesh) OR case-control studies (TIAB) OR retrospective studies (Mesh) OR retrospective studies (TIAB) OR case-control study (TIAB) OR case-comparison studies (TIAB) OR cohort studies (Mesh) OR cohort studies (TIAB) OR case (TIAB) OR cohort (TIAB) OR ratio (TIAB) OR risk (TIAB) OR prospective (TIAB) OR follow (TIAB). The search strategy was slightly modified based on the specific criteria of each database (Complementary Material - - Table S1). In addition, reference lists from the included articles and gray literature were searched manually.

The retrieved studies were assessed and classified according to the eligibility criteria. After duplicate removal, two authors (Pereira P. P. S. and Mata F. A. F.) screened the titles and abstracts, and assessed the full texts articles according to the eligibility criteria. Disagreements were settled by consensus.

\section{Data Extraction}

A standardized data extraction form was used to gather the following information: title, last name of the first author, country and city, data collection date, publication date, sample characteristics (size, sampling method, and age), exposure and outcome measures, follow-up period of cohort studies, controlled confounder variables, and estimated risk with respective confidence intervals (CIs). Data was extracted from systematic reviews in cases in which the primary studies did not give enough information to calculate association measures. Data were independently extracted by the two investigators (Pereira P. P. S. and Mata F. A. F.).

\section{Quality Assessment}

The Newcastle-Ottawa Scale was used for the methodological quality assessment, which is recommended by the Cochrane Collaboration for cohort and case-control studies. ${ }^{12}$ This scale evaluates eight items on three perspectives: (1) group selection, (2) group comparability, and (3) determination of any exposure or outcome to case-control or cohort studies. Each question receives one point (marked as ${ }^{*}$ ), except for the comparability item, which may receive one or two points. A total score varying between one and three indicates a lowquality study, between four and six an average-quality study, and from seven to nine points a high-quality study.

\section{Data Synthesis}

The outcome of interest was LBW (with maternal exposure to alcohol during pregnancy). We considered as risk measures the relative risk (RR) for prospective cohorts and retrospective cohorts with a $95 \% \mathrm{CI}$ and odds ratio (OR) for case-control. A random effect meta-analysis was performed using the inverse variance method when I-squared $\left(\mathrm{I}^{2}\right)>40 \%$, and when $\mathrm{I}^{2}<40 \%$, the meta-analysis used a fixed-effect model. ${ }^{13}$

The statistical heterogeneity between studies was assessed using both the Cochrane $\mathrm{Q}$ test and $\mathrm{I}^{2}$ statistic. Higgins and Thompson ${ }^{13} \mathrm{I}^{2}$ statistic was used to evaluate the magnitude of the inconsistency, where $\mathrm{I}^{2}>50 \%$ was classified as high heterogeneity, between 25 and $50 \%$ as average, and $<25 \%$ as low. ${ }^{14} \mathrm{~A}$ Galbraith ${ }^{15}$ plot was adopted to show the studies that resulted in heterogeneity. As clinical and methodological differences may be sources of heterogeneity, the data were analyzed by meta-regression, subgroup, and sensitivity analyses to explore these differences.

The meta-regression aimed to investigate the influences of the methodological quality score, of the number of confounders, of the publication year, of the year of data collection, and of the sample size on the summarized measure of effect. The subgroup analysis was performed by sample size $(<1,000$ versus $>1,000)$, by the type of measure (crude versus adjusted), by the quality of the study (low, average, and high), by the year of publication (1980-1989, 19901999, 2000-2009, 2010- 2016), and by geographic region (Americas, Europe, Africa, Asia, and Oceania).

Publication bias was evaluated by Begg funnel plot and by Egger regression $(p<0.05) \cdot{ }^{16}$ All of the statistical analyses were conducted using Stata 13.0 (StataCorp, College Station, TX, USA).

\section{Results}

\section{Study Selection}

We have identified 2,376 studies from databases, and 7 from manual search on reference lists (total of 2,383). From these, 472 duplicates were excluded, and 76 studies were selected for eligibility assessment, resulting in 39 studies included in the present review (-Fig. 1). 


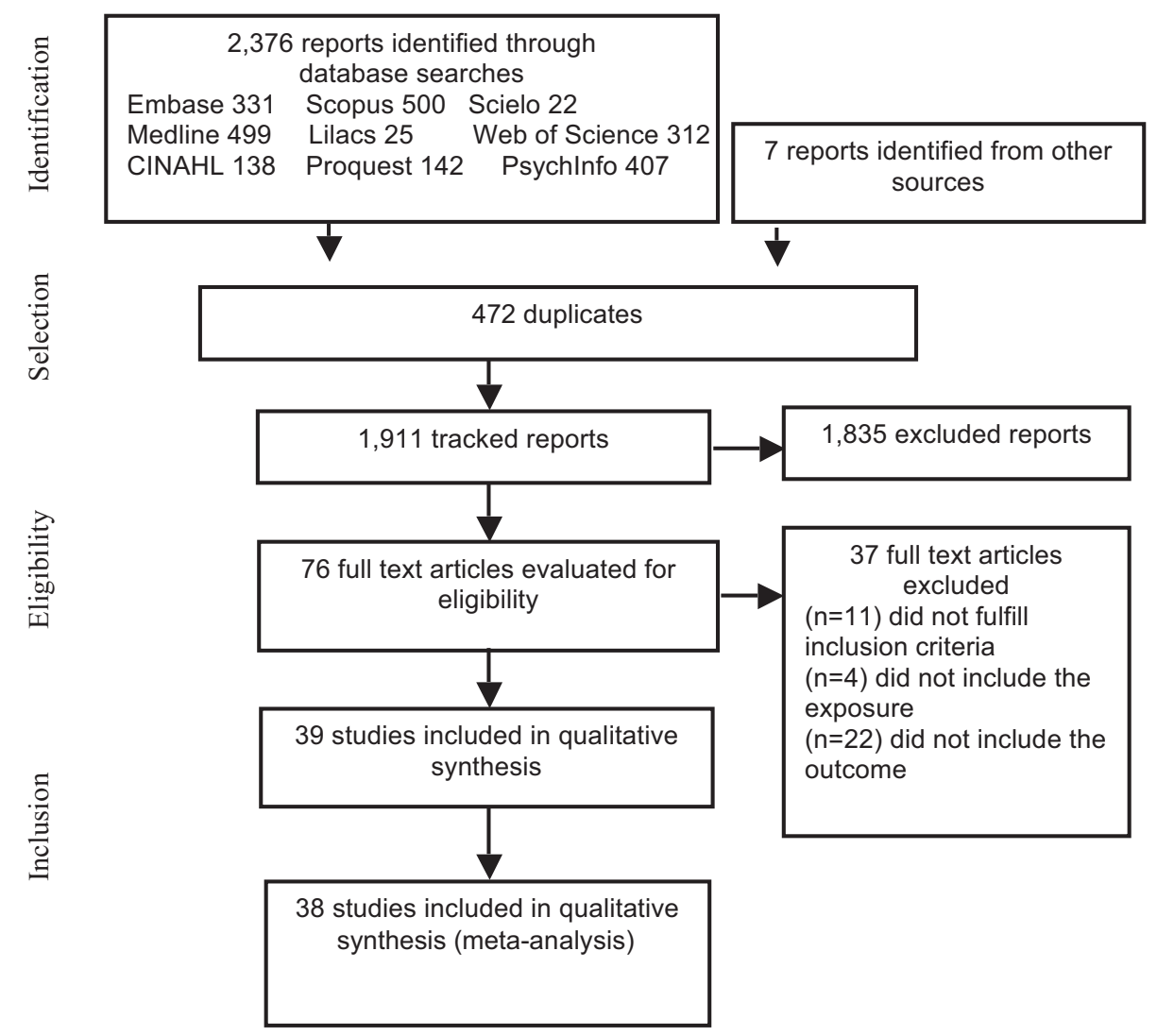

Fig. 1 Flowchart of article eligibility and final inclusion in the present systematic review.

\section{Study Characteristics}

A total of 39 studies were included in the present review, comprising 497,023 women. A total of 21 studies were conducted in the Americas, 12 in Europe, 3 in Asia, 2 in Oceania, and 1 in Africa (-Table 1).

A total of 8 studies were published in the 1980's, and the oldest was published in the United States of America. ${ }^{17} \mathrm{~A}$ total of 12 studies were published between 1990 and 1999, and the other ones were published between 2000 and 2016. We have included 15 retrospective studies, 20 prospective cohort studies, and 4 case-control.

The studies included 19 provided only the crude association measure and 20 studies showed adjusted measures. The most considered confounding variables were: age, income, education, marital status, body mass index (BMI), gestational morbidities, and number of prenatal appointments.

A total of 19 studies reported the drinking pattern during pregnancy, including the number of alcoholic drinks per day, 27,37,39,42,54 and per week. 20,22,26,33,38,39,44,46,55 The studies included also reported the amount of alcohol (g) consumed monthly, ${ }^{25,27}$ and the number of drinking occasions in the previous year. ${ }^{22}$ Three studies reported some type of classification for consumption (light, moderate, and heavy; abuse or dependence), ${ }^{23,31,32}$ and one study showed results by type of beverage. ${ }^{22}$ A total of 5 studies showed results by gestational age, ${ }^{19,21,30,33,34}$ and only 1 reported measures by birthweight $(<1,500 \mathrm{~g}$ and $<2,500 \mathrm{~g}){ }^{31}$
The majority of the studies had high quality, 13 had average quality, ${ }^{17,23,25,27,31,36,38-43}$ and 1 had low methodological quality. ${ }^{44}$

\section{Association Between Maternal Exposure to Alcohol and Low Birthweight}

From the studies included in the qualitative synthesis, 38 were included in the meta-analysis. A study was excluded from the meta-analysis because it did not present the $\mathrm{CI}$ of the summary measure and it was not possible to calculate the measure. ${ }^{40}$ The meta-analysis for retrospective cohort studies showed that maternal exposure to alcohol was associated with LBW $\left(\mathrm{RR}=1.37 ; 95 \% \mathrm{Cl}: 1.10-1.71 ; \mathrm{I}^{2}=98.4 \% ; p<0.01\right.$; - Fig. 2$)$. This association was not observed for prospective cohort studies $\left(\mathrm{RR}=1.11 ; 95 \% \mathrm{CI}: 0.98-1.25 ; \mathrm{I}^{2}=81.5 \% ; p<0.01 ;\right.$ - Fig. 3 ), or case-control studies (OR = 1.16; 95\%CI: 0.68-1.97; $\mathrm{I}^{2}=61.2 \%$; $p=0.05$; - Fig. 4).

\section{Publication Bias}

The Egger test and the visual inspection of the funnel plot indicated no publication bias among the studies included in the meta-analysis (retrospective cohort studies: $p=0.23$; prospective cohort studies: $p=0.31$; and case-control studies: $p=0.14$ ).

\section{Sensitivity Analysis}

For retrospective cohort studies, the value of heterogeneity was 98.4\%. The Galbraith plot showed that six studies $25,36,45-48$ were the main sources of heterogeneity (Complementary 


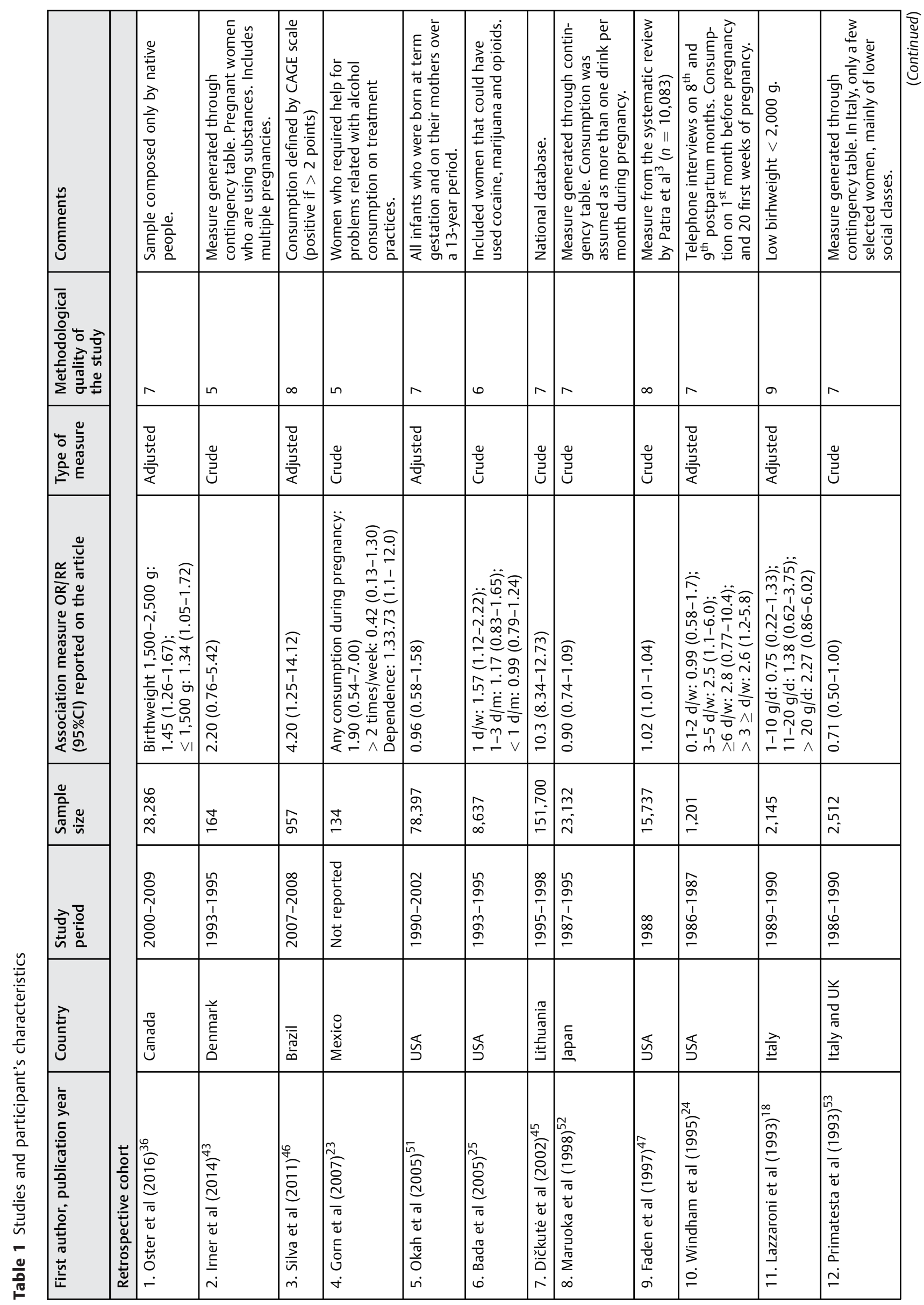




\begin{tabular}{|c|c|c|c|c|c|c|c|c|}
\hline 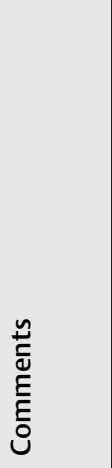 & 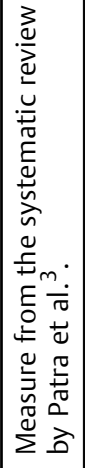 & 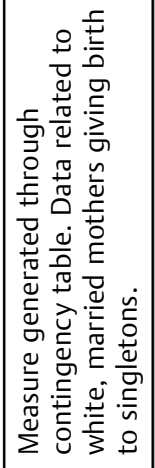 & 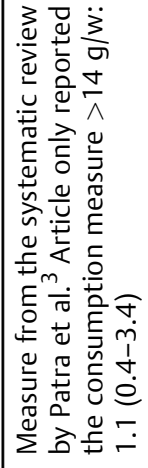 & & 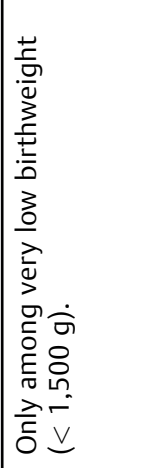 & 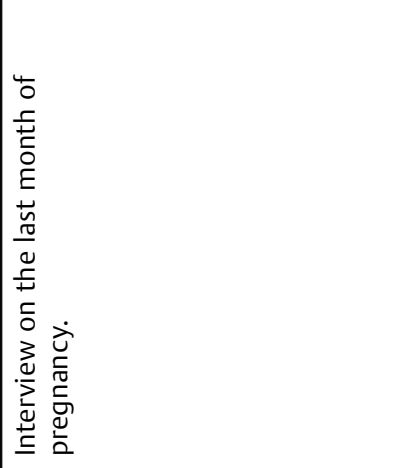 & 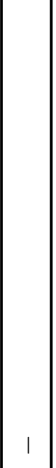 & 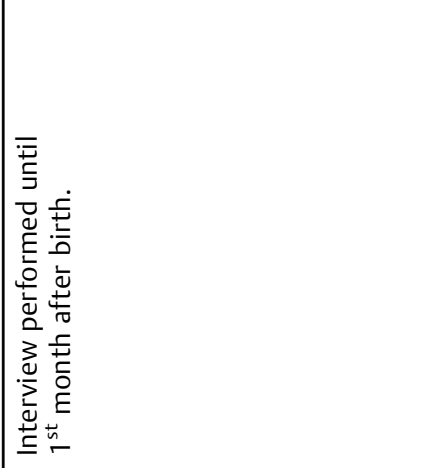 \\
\hline 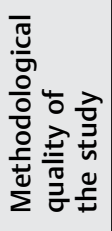 & a & in & 0 & & $\infty$ & $r$ & $a$ & a \\
\hline 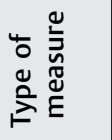 & 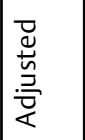 & 妾 & $\frac{\pi}{2}$ & & 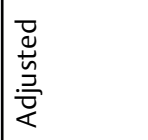 & 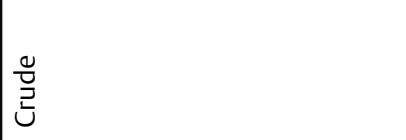 & 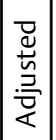 & 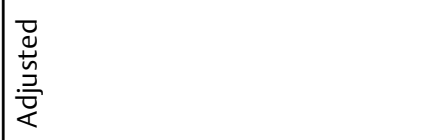 \\
\hline 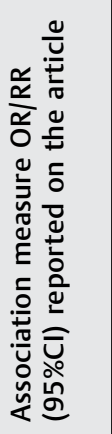 & $\begin{array}{l}f \\
\sigma \\
o \\
0 \\
1 \\
o \\
0 \\
0 \\
0 \\
0 \\
0 \\
0\end{array}$ & 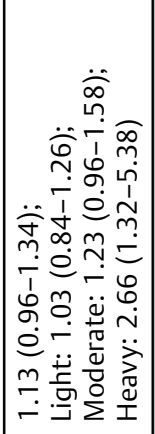 & 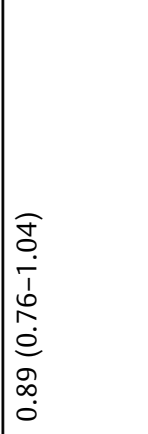 & & 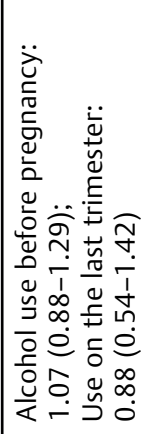 & 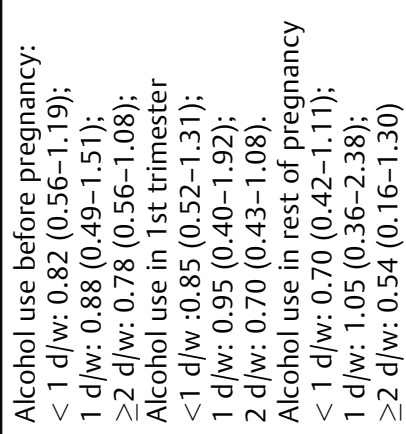 & 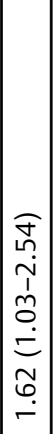 & 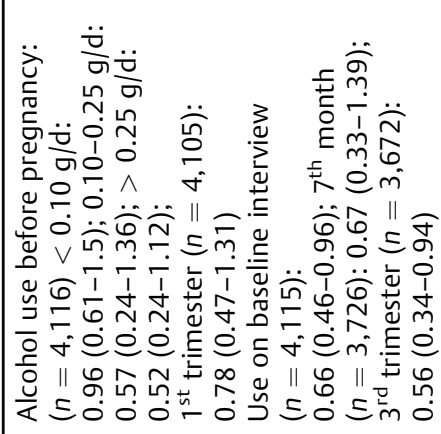 \\
\hline 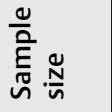 & 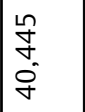 & \begin{tabular}{l}
8 \\
\multirow{4}{+}{} \\
in
\end{tabular} & $\begin{array}{l}\stackrel{g}{d} \\
\stackrel{d}{\simeq}\end{array}$ & & $\begin{array}{l}\stackrel{0}{m} \\
\text { m. } \\
\sigma\end{array}$ & $\begin{array}{l}\approx \\
\infty \\
0 \\
6\end{array}$ & $\begin{array}{l}\stackrel{0}{1} \\
m \\
-\end{array}$ & 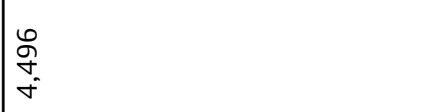 \\
\hline 勇范 & 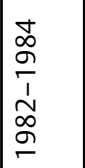 & 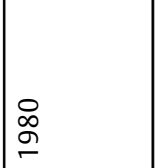 & $\begin{array}{l}\infty \\
\stackrel{2}{\simeq}\end{array}$ & & ¿্口 & 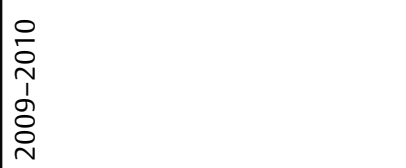 & 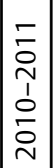 & 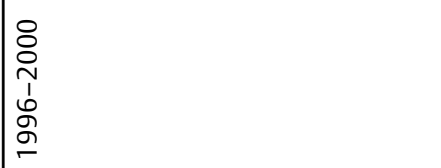 \\
\hline 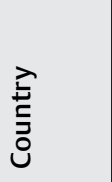 & $\begin{array}{l}\frac{\pi}{0} \\
\stackrel{0}{\tilde{0}} \\
\text { U. }\end{array}$ & 芩 & 芩 & & 芩 & 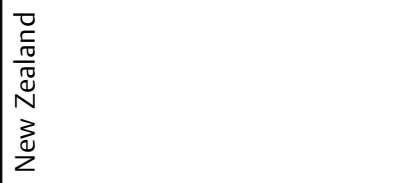 & $\mid$\begin{tabular}{|l}
$\overline{\bar{N}}$ \\
$\frac{\tilde{D}}{\Delta}$
\end{tabular} & 芯 \\
\hline 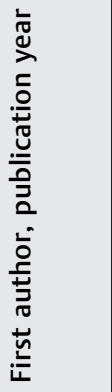 & 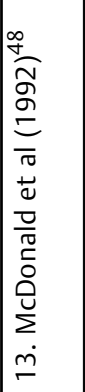 & 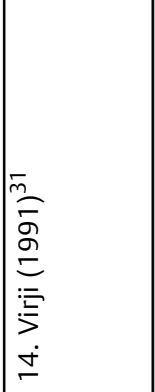 & 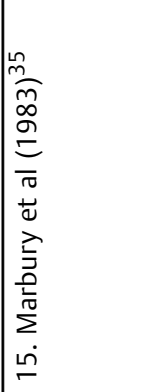 & 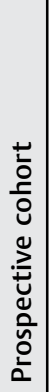 & 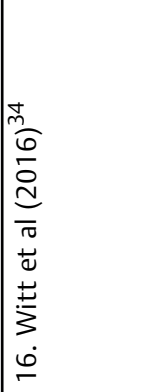 & 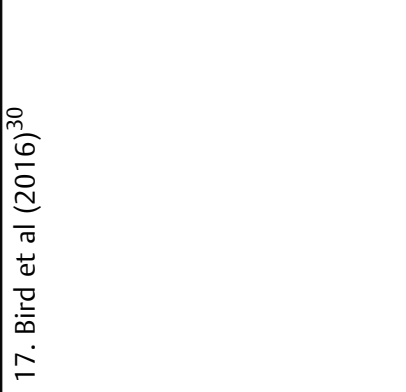 & 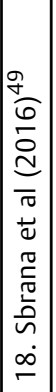 & 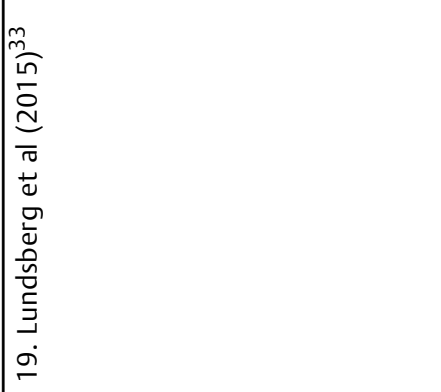 \\
\hline
\end{tabular}




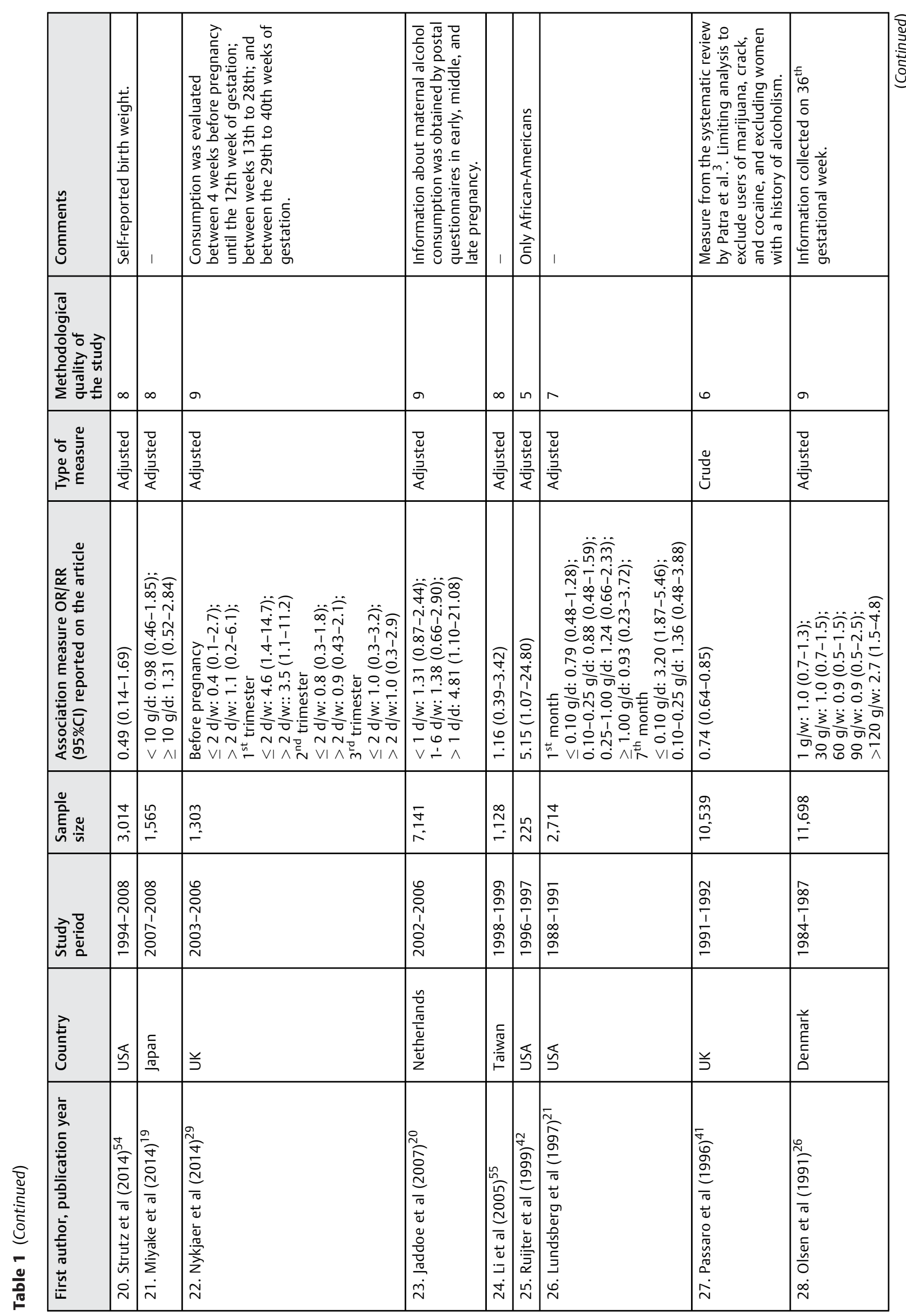




\begin{tabular}{|c|c|c|c|c|c|c|c|c|c|c|c|}
\hline 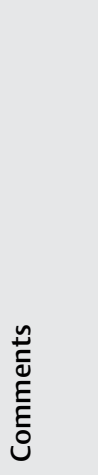 & 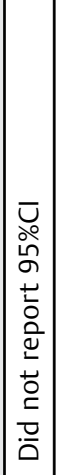 & 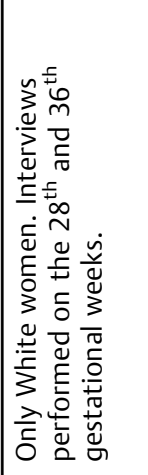 & 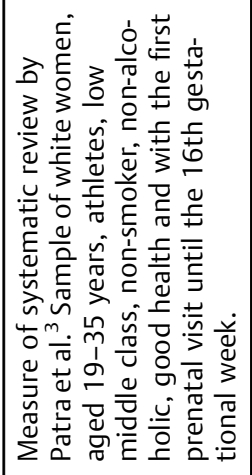 & 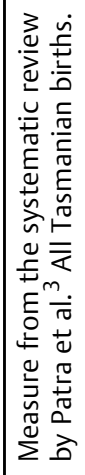 & & 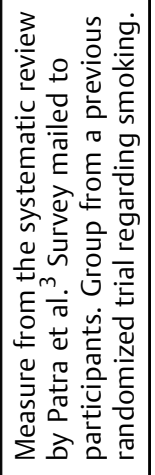 & 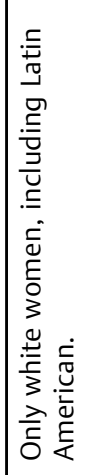 & & & & \\
\hline 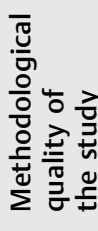 & in & $\wedge$ & in & $r$ & 0 & in & in & & $m$ & $\wedge$ & $\wedge$ \\
\hline 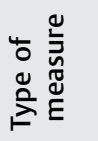 & $\frac{0}{0}$ & $\frac{\stackrel{0}{2}}{2}$ & 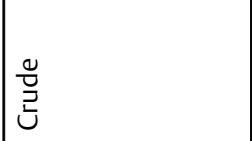 & $\frac{\mathscr{v}}{2}$ & $\frac{\pi}{2}$ & $\frac{\mathscr{v}}{\tilde{v}}$ & $\frac{\pi}{\tilde{z}}$ & & 立 & 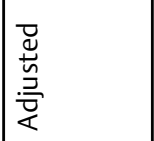 & 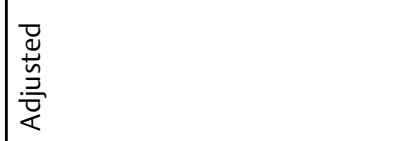 \\
\hline 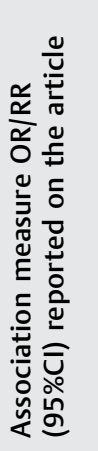 & 号 & 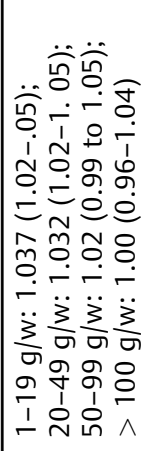 & 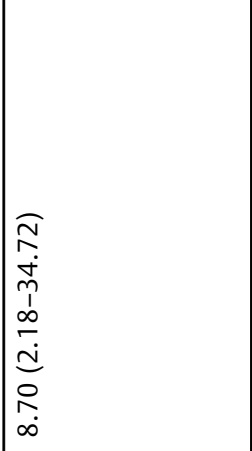 & 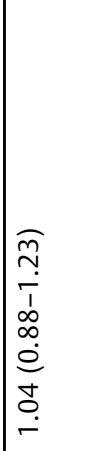 & 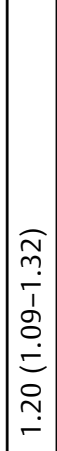 & 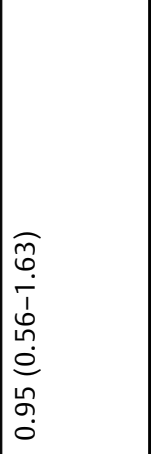 & 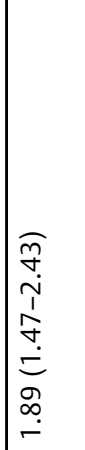 & & 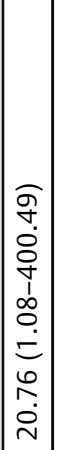 & 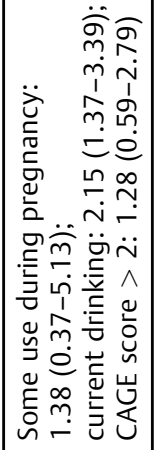 & 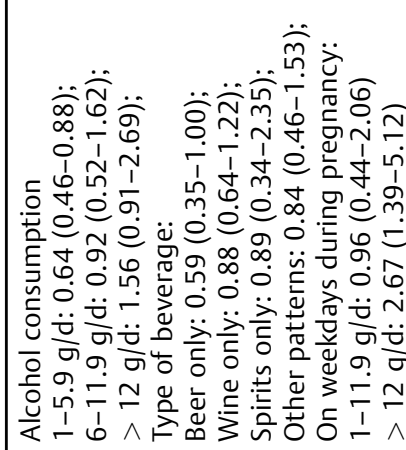 \\
\hline 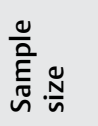 & 윰 & $\stackrel{m}{\frac{m}{n}}$ & $\underset{\sim}{\stackrel{\Xi}{\prime}}$ & $\begin{array}{l}\frac{a}{m} \\
0 \\
0\end{array}$ & $\mid \begin{array}{l}\tilde{m} \\
\stackrel{n}{n} \\
\bar{m} \\
\dot{m}\end{array}$ & $\stackrel{\stackrel{0}{n}}{\stackrel{\stackrel{n}{r}}{-}}$ & 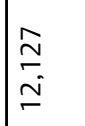 & & 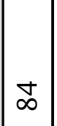 & ঃ & $\mid \begin{array}{l}\tilde{8} \\
i \\
i\end{array}$ \\
\hline 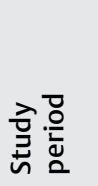 & 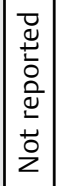 & 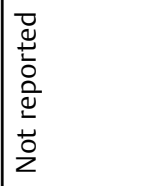 & 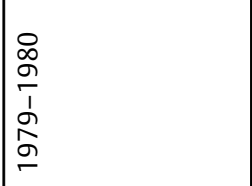 & 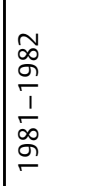 & 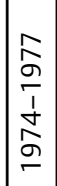 & 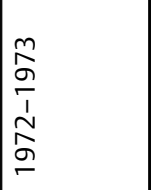 & 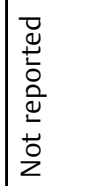 & & 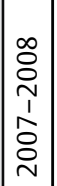 & 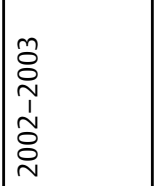 & 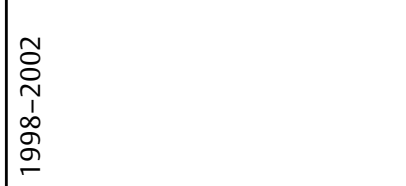 \\
\hline 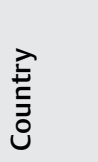 & 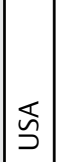 & 弚 & 弚 & 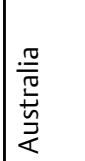 & 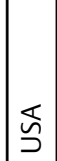 & 弚 & 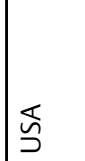 & & 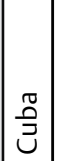 & 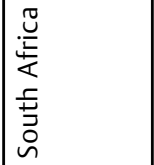 & $\mid \begin{array}{l}\text { 离 } \\
\text { ஸิ }\end{array}$ \\
\hline 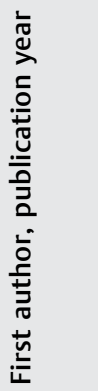 & 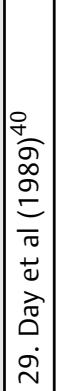 & 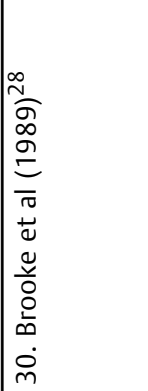 & 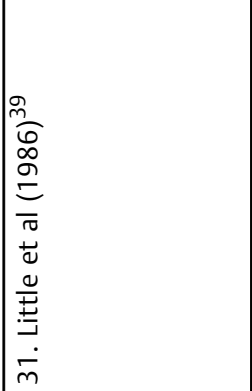 & 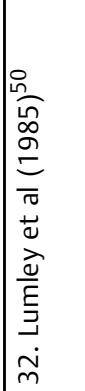 & 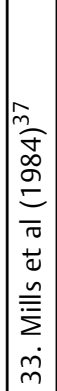 & 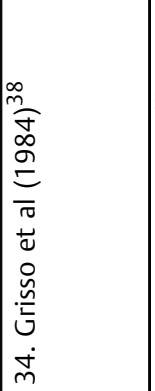 & 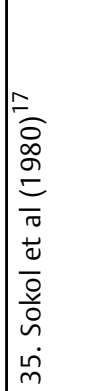 & 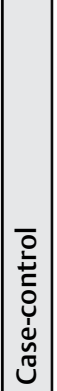 & 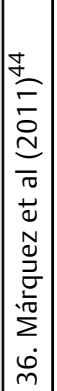 & 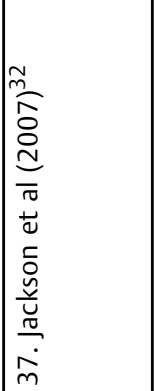 & 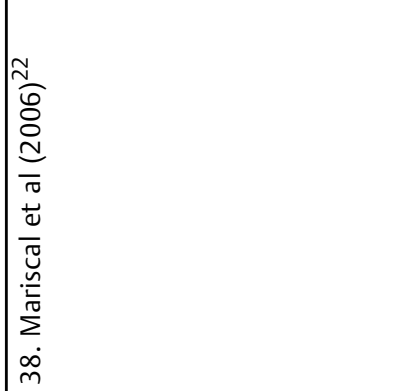 \\
\hline
\end{tabular}




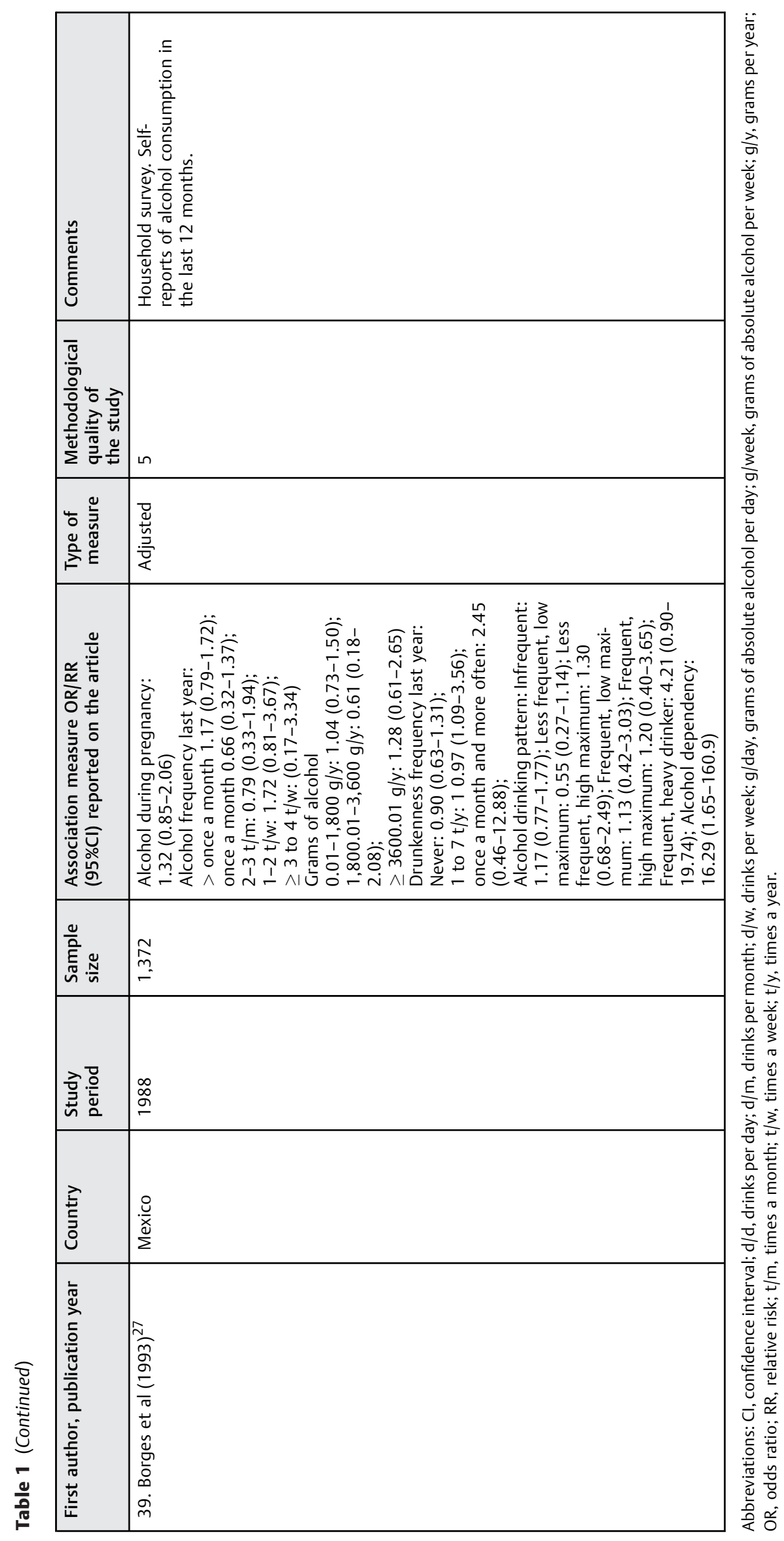




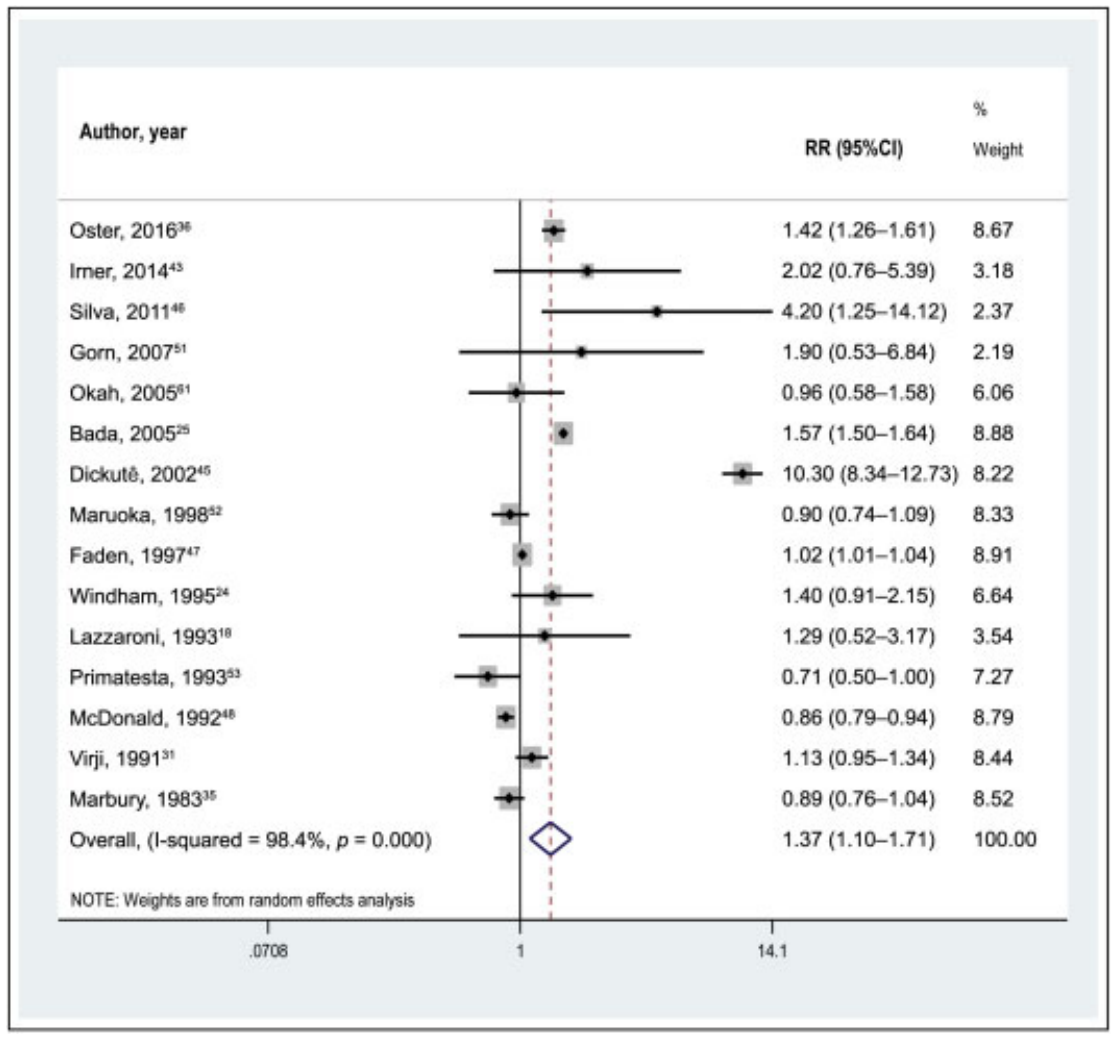

Fig. 2 Effect of prenatal alcohol exposure on low birthweight $(<2,500 \mathrm{~g})$ for retrospective cohort studies. Abbreviations: Cl, confidence interval; RR, relative risk.

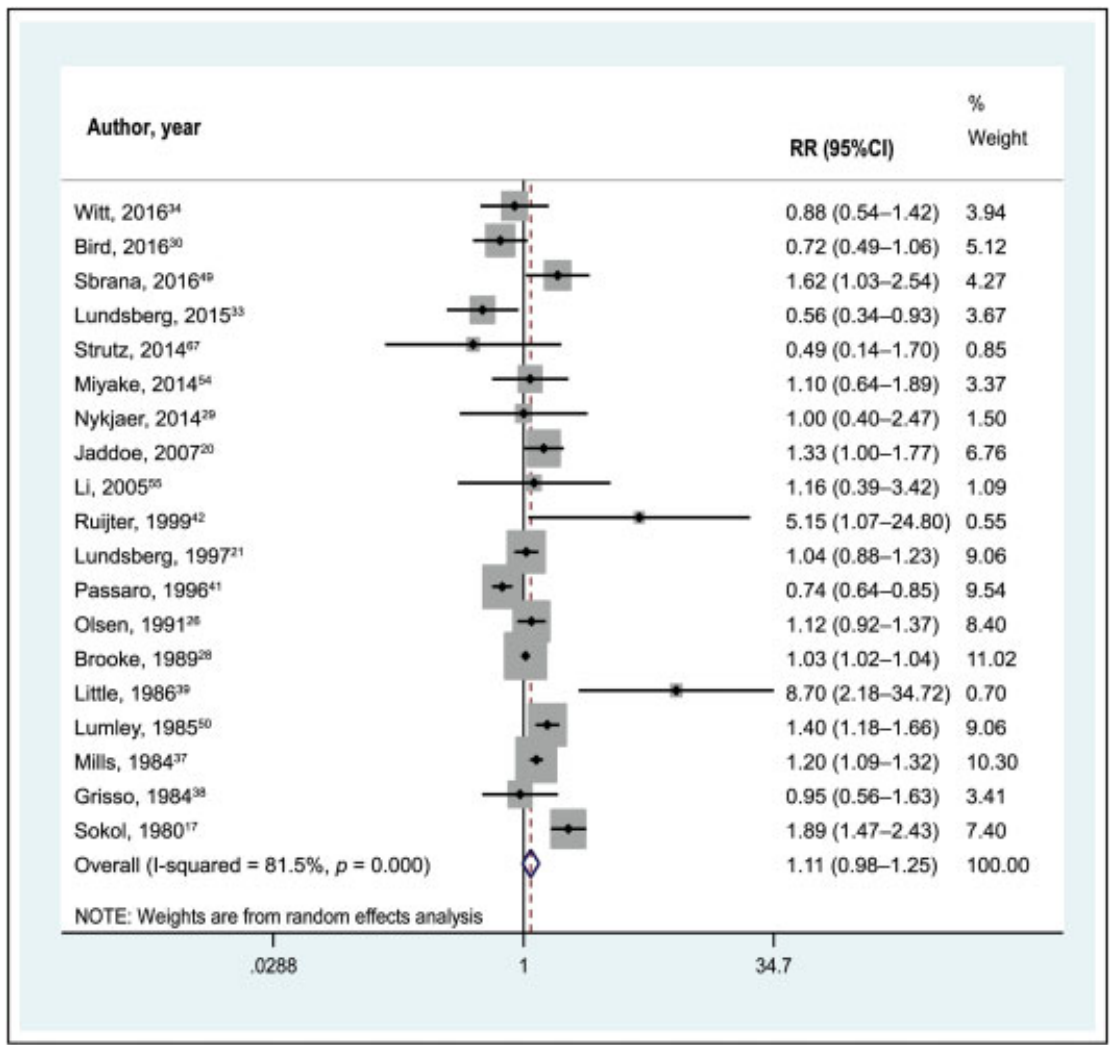

Fig. 3 Effect of prenatal alcohol exposure on low birthweight $(<2,500 \mathrm{~g})$ for prospective cohort studies. Abbreviations: $\mathrm{Cl}$, confidence interval; $\mathrm{RR}$, relative risk. 


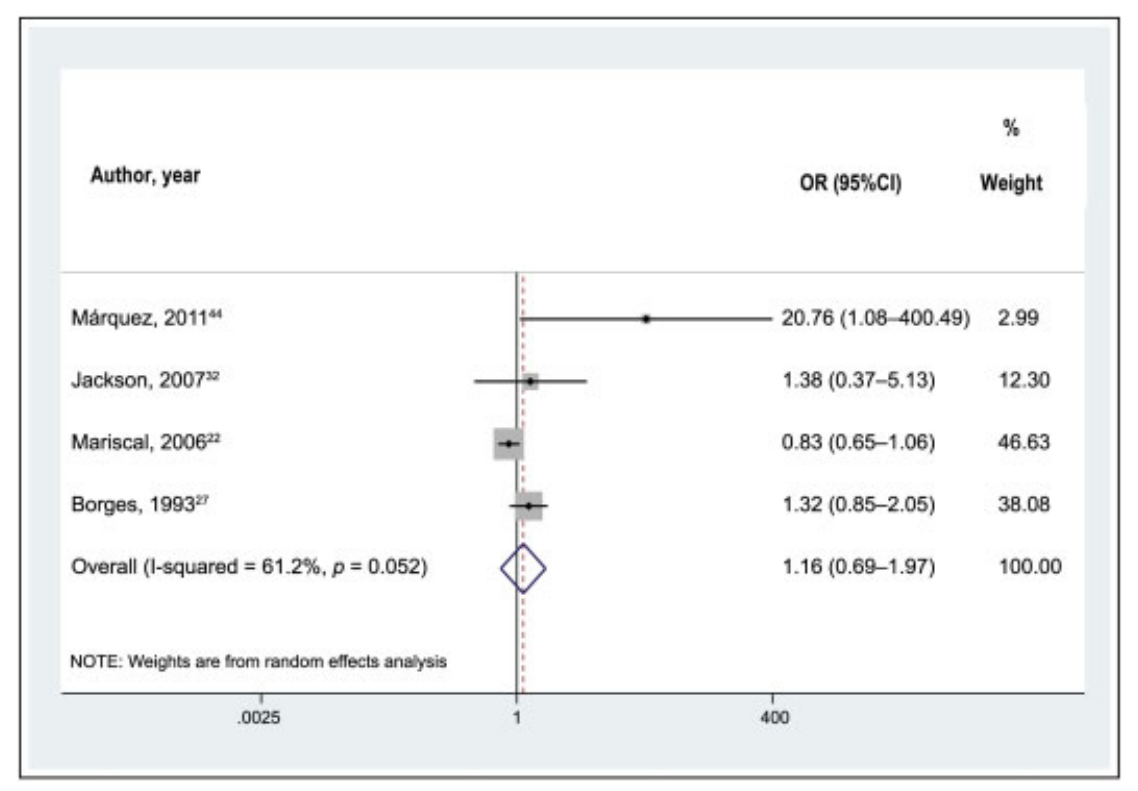

Fig. 4 Effect of prenatal alcohol exposure on low birthweight $(<2,500 \mathrm{~g})$ for case-control studies.

Material --Fig. S1). The meta-analysis performed without including the aforementioned studies showed no association $\left(\mathrm{RR}=0.99 ; 95 \% \mathrm{CI}: 0.86-1.15 ; \mathrm{I}^{2}=44.0 \%\right)$. Eight prospective cohort studies were the main sources of heterogeneity $^{28,33,38,39,41,42,49,50}$ (Complementary Material - Fig. S2). The $\mathrm{I}^{2}$ value of heterogeneity decreased from $81.5 \%$ to $62.4 \%$ after excluding those 10 studies and the meta-analysis performed showed association ( $R R=1.14 ; 95 \% C I$ : 0.98-1.33). One case-control study reported a discrepant OR and a sample size $<100$ participants, ${ }^{44}$ and the summarized OR excluding this study was 1.02 (95\%CI: $0.60-1.74 ; \mathrm{I}^{2}=43.6 \% ; p=0.17$ ).

\section{Subgroup Analysis}

Among the retrospective cohort studies, those that reported a crude association measure or those published between 2010 and 2016, regardless of their sample size, maintained the association between alcohol consumption and LBW (-Table 2).

In prospective cohorts, two studies with sample sizes $<1,000$ showed a strong association between exposure and outcome ( $R R=6.92 ; 95 \% \mathrm{CI}: 2.54-19.55)$. We have also observed an association between exposure and outcome in the studies published in the period between 1980 and 1989.

One case-control study recently published, reporting crude association measure, and with low methodological quality, showed a significant association between maternal exposure to alcohol during pregnancy and LBW. ${ }^{44}$

\section{Heterogeneity Tests}

High heterogeneity was observed between the studies. The results of the meta-regression indicated that part of the heterogeneity between retrospective cohort studies can be explained by sample size $(p<0.01)$. The higher the sample size, the stronger the association between maternal alcohol consumption and LBW (Complementary Material - - Fig. S3). However, among prospective cohorts, sample size did not explain the high heterogeneity. Meta-regressions were not performed due to the small number of case-control studies $(n=4)$.

Publication year, data collection year, number of confounder variables, and methodological quality did not explain the heterogeneity among cohort studies.

\section{Discussion}

In the present systematic review, maternal alcohol consumption was identified as a risk factor for LBW according to retrospective cohort studies. However, an association was observed for cohort and case-control studies when subgroup analysis was performed for sample size, crude or adjusted measure, methodological quality, and publication year.

We have found three systematic reviews on the subject. Henderson et al ${ }^{10}$ performed two systematic reviews on this subject. The first one, about binge drinking (considered more than 5 doses in 2 hours) included 14 original studies. ${ }^{10}$ They concluded that the available evidence about the negative effects of binge drinking were not consistent. Their second review referred to moderate alcohol use. They included 19 cohort studies majorly performed in the United States of America. Only one study indicated moderate alcohol consumption as a risk factor for LBW, and seven studies described moderate use as a protective factor. ${ }^{11}$

A systematic review by Patra et $\mathrm{al}^{3}$ performed between 1980 and 2009 included 28 studies sampled from countries in the Americas, Europe, Africa, and Oceania. These authors showed a RR of 1.12 (95\%CI: $\left.1.04-1.20 ; \mathrm{I}^{2}=80 \%\right)$ toward the relationship between alcohol consumption during pregnancy and LBW. They also evaluated the dose-response effect among the 19 included studies. They found that a daily consumption of $10 \mathrm{~g}$ of alcohol (around one and a half shots of an alcoholic beverage) did not show an effect on BW. However, alcoholic drink intake above this measure showed a linear relationship between alcohol use and BW decrease. 


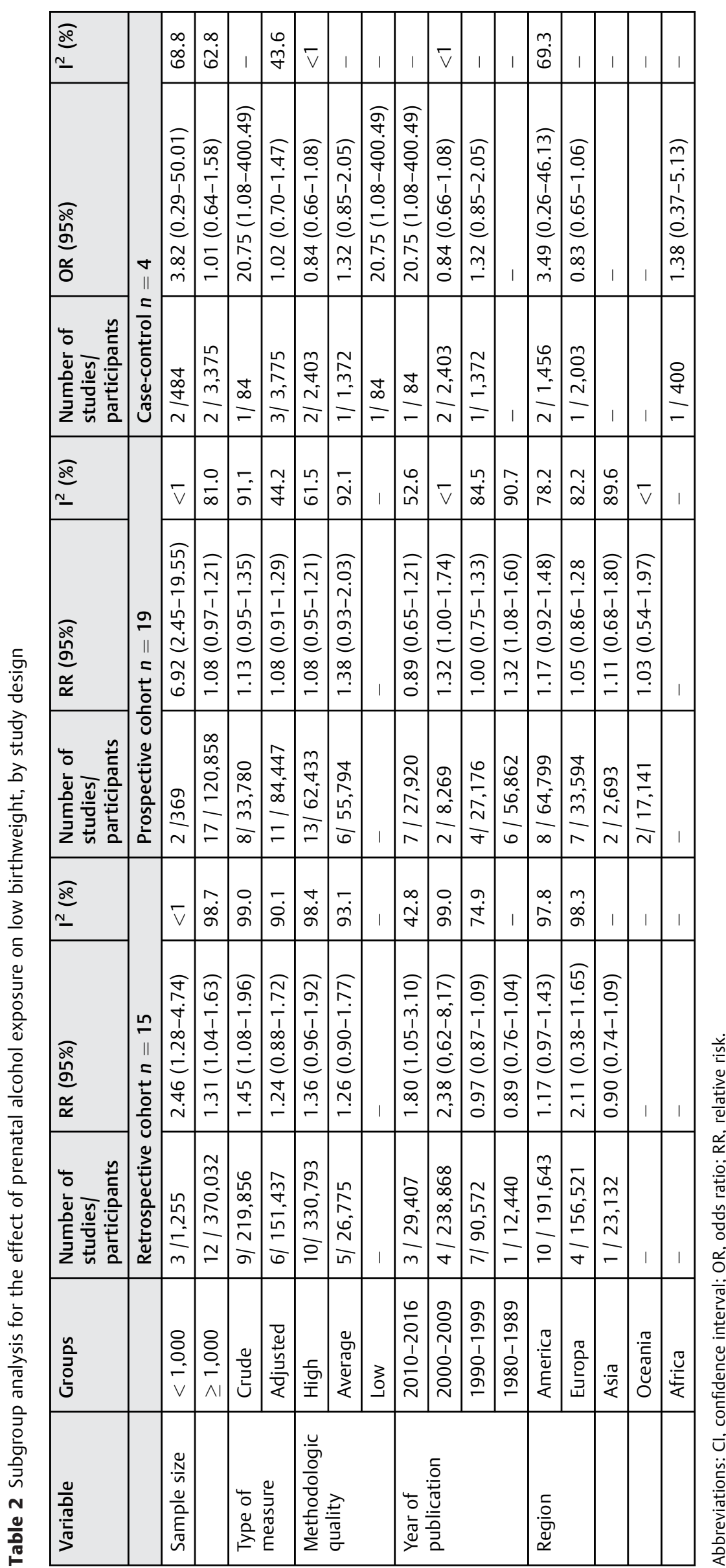


The authors of the systematic review with meta-analysis already published ${ }^{3}$ did not investigate the causes for high heterogeneity among the primary studies included (80\%). We sought to investigate the causes for heterogeneity in our systematic review, which may be due to methodological differences among the studies and sample specificities. The results of the meta-regression indicated that part of the heterogeneity between retrospective cohort studies can be explained by the sample size. Also in the subgroup analysis, prospective cohorts with sample size $<1,000$ showed a strong association with LBW. We do not know whether it is the larger or the smaller studies that give the better answer. We believe particularly with measures of diet where the smaller studies can potentially use more in depth measures. In the sensitive analysis, six retrospective studies were the main sources of heterogeneity. Of these six studies, three used information from databases, one study limited the sample to race, ${ }^{36}$ and one study limited the age of the subjects (until 28 years old). ${ }^{47}$ In addition, one study used CAGE screening questionnaire for alcohol use for excessive drinking and alcoholism. ${ }^{19}$ Eight prospective studies were the main sources of heterogeneity, five were of average methodological quality, four limited the sample to race, ${ }^{17,28,39,42}$ and one study quantified the consumption of alcohol by means of laboratory tests. ${ }^{38}$ The Galbraith plot showed that these studies are responsible for the high heterogeneity in the meta-analysis, and that they used very specific samples: limiting the sample by race, by specific ways to measure alcohol consumption (CAGE and laboratory examination), and by having average methodological quality.

In view of the results of the present systematic review, it is important to consider information bias and residual confounding. Self-reported alcohol consumption may underestimate the association between exposure and outcome. Only one study dosed the alcohol consumption by means of a laboratory examination. ${ }^{38}$ The moment and the method of questioning consumption may introduce information bias. For example, an interview taken after the birth of a child, when adverse effects or the nonoccurrence of these effects are already apparent, may influence the response of the woman about her exposure to substances. As women with healthy newborns may not feel embarrassed when reporting alcohol consumption during pregnancy, women with adverse outcomes during pregnancy or after the birth of their children may not report the actual consumption because they may feel guilty or misjudged. $3,41,56$

Residual confounding may also have contributed to the lack of association between alcohol and LBW. Even after adjustment, nutritional and socioeconomic aspects may not have been well measured due to inaccuracies of their measurements. ${ }^{3}$ Pregnant women who drank during pregnancy may have been healthier in terms of nutrition, lifestyle, and health state, and they might have consumed alcohol at moderate quantities and might not have smoked. ${ }^{57,58}$ A study showed that women who consumed alcoholic beverages moderately also consumed less animal meat, egg, dairy fat, and consumed more fruits, vegetables, and carbohydrates. ${ }^{59}$
In the present review, we have evaluated the alcohol exposure dichotomously. A total of 19 studies showed the drinking patterns of pregnant women. However, these measures were not summarized due to differences among consumption categorization across studies. Low, moderate, or heavy alcohol consumption may influence a higher or lower decrease on BW. Heavy drinking is well-established in the literature as a risk factor for low $\mathrm{BW}^{3,10,22,37}$ A low to moderate consumption or occasional drinking may not have a statistically significant association or even be identified as a protective factor. $^{11,18,21,24,31,47,60,61}$

The physiological explanation for moderate drinking as a protective factor is related to the effects on the maternal cardiovascular system. Alcohol activates endogenous plasminogen, which increases fibrinolytic activity, inhibiting placental aggregation. It also influences the hemostatic mechanism of blood vessels by promoting relaxation, leading to higher growth levels of the vascular endothelium. These vascular alterations contribute to better placental development and increases in fetal oxidation and nutrition, which reflect on the growth pattern. ${ }^{62-64}$

It is important to highlight that although the majority of studies indicate that moderate drinking is not considered a risk factor for low birthweight, many studies note the association between drinking and other outcomes related to the growth and development of the child. Some cognitive and behavioral changes during infancy and adolescence, such as difficulty to follow instructions, aggressive behavior, risk of eating disorders, hyperactivity, and other mental disorders, were found to be associated with low maternal exposure to alcohol. ${ }^{60,65-68}$

Among the strengths of the present study, we have investigated the causes for the high heterogeneity found in the meta-analysis, so we believe that our systematic review may contribute to the discussion of the main causes for heteronomy between primary studies on alcohol consumption and outcomes on newborns. Besides that, we have aimed to reach the recommendations for conducting a good systematic review, including: sensitive literature search, no publication language or date restrictions, inclusion of a gray literature search, and study selection, data extraction, and methodological assessment performed independently by at least two authors. The present systematic review followed the Moose Guidelines for Meta-Analyses and Systematic Reviews of Observational Studies. ${ }^{69}$

\section{Conclusion}

We did not find an association between alcohol consumption during gestation and LBW in the analysis in all subgroups. In addition, we have found high heterogeneity between the primary studies, and this is related to methodological differences in the conduction of these studies. As relevant directions for future studies, we suggest that primary studies investigate the association between maternal exposure to alcohol and the adverse effects on fetal health, considering the many levels of consumption and different populations. Methodological variations between the studies and the different assortment of alcohol consumption tools may 
introduce a misclassification and impair a comparison between the studies. We recommend that future studies on this subject use validated data collection tools and standardized methods for describing alcohol consumption among pregnant women.

\section{Conflicts of interests}

The authors have no conflicts of interests to declare.

\section{References}

1 Centers for Disease Control and Prevention (CDC). Alcohol use and binge drinking among women of childbearing age-United States, 2006-2010. MMWR Morb Mortal Wkly Rep 2012;61(28):534-538http://www.cdc.gov/mmwr/preview/mmwrhtml/ mm6128a4.htm. Accessed December 15, 2017

2 Finnegan L. Substance Abuse in Canada: Licit and Illicit Drug Use During Pregnancy: Maternal, Neonatal and Early Childhood Consequences. Ottawa, ON: Canadian Centre on Substance Abuse; 2013

3 Patra J, Bakker R, Irving H, Jaddoe VW, Malini S, Rehm J. Doseresponse relationship between alcohol consumption before and during pregnancy and the risks of low birthweight, preterm birth and small for gestational age (SGA)-a systematic review and meta-analyses. BJOG 2011;118(12):1411-1421. Doi: 10.1111/ j.1471-0528.2011.03050.x

4 Carson G, Cox LV, Crane J, et al; Society of Obstetricians and Gynaecologists of Canada. Alcohol use and pregnancy consensus clinical guidelines. J Obstet Gynaecol Can 2010;32(08, Suppl 3): S1-S31

5 Chang G. Alcohol Intake and Pregnancy. 2015https://www.uptodate.com/contents/alcohol-intake-and-pregnancy. Accessed December 15, 2017.

6 Little RE. Moderate alcohol use during pregnancy and decreased infant birth weight. Am J Public Health 1977;67(12):1154-1156

7 Edmond K, Bah R. Optimal Feeding of Low-Birth-Weight Infants: Technical Review. Geneva: World Health Organization; 2006. https://www.who.int/maternal_child_adolescent/documents/ 9241595094/en/

8 World Health Organization. Care of the Preterm and Low-BirthWeight Newborn: World Prematurity Day - 17 November 2018. Geneva: World Health Organization; 2018http://www.who.int/ maternal_child_adolescent/newborns/prematurity/en/. Accessed December 10, 2018.

9 McCowan L, Horgan RP. Risk factors for small for gestational age infants. Best Pract Res Clin Obstet Gynaecol 2009;23(06): 779-793. Doi: 10.1016/j.bpobgyn.2009.06.003

10 Henderson J, Kesmodel U, Gray R. Systematic review of the fetal effects of prenatal binge-drinking.J Epidemiol Community Health 2007;61(12):1069-1073. Doi: 10.1136/jech.2006.054213

11 Henderson J, Gray R, Brocklehurst P. Systematic review of effects of low-moderate prenatal alcohol exposure on pregnancy outcome. BJOG 2007;114(03):243-252. Doi: 10.1111/j.14710528.2006.01163.X

12 Wells GA, Shea B, O'Connell D, et al. The Newcastle-Ottawa Scale (NOS) for Assessing the Quality of Nonrandomised Studies in Meta-Analyses. 2014http://www.ohri.ca/programs/clinical_epidemiology/oxford.asp. Accessed December 15, 2017.

13 Higgins JPT, Thompson SG. Quantifying heterogeneity in a metaanalysis. Stat Med 2002;21(11):1539-1558. Doi: 10.1002/ sim.1186

14 Mantel N, Haenszel W. Statistical aspects of the analysis of data from retrospective studies of disease. J Natl Cancer Inst 1959;22 (04):719-748
15 Galbraith RF. A note on graphical presentation of estimated odds ratios from several clinical trials. Stat Med 1988;7(08):889-894. Doi: $10.1002 / \operatorname{sim} .4780070807$

16 Egger M, Davey Smith G, Schneider M, Minder C. Bias in metaanalysis detected by a simple, graphical test. BMJ 1997;315 (7109):629-634. Doi: 10.1136/bmj.315.7109.629

17 Sokol RJ, Miller SI, Reed G. Alcohol abuse during pregnancy: an epidemiologic study. Alcohol Clin Exp Res 1980;4(02):135-145. Doi: 10.1111/j.1530-0277.1980.tb05628.x

18 Lazzaroni $\mathrm{F}$, Bonassi S, Magnani $\mathrm{M}$, et al. Moderate maternal drinking and outcome of pregnancy. Eur J Epidemiol 1993;9 (06):599-606. Doi: 10.1007/BF00211433

19 Miyake Y, Tanaka K, Okubo H, Sasaki S, Arakawa M. Alcohol consumption during pregnancy and birth outcomes: the Kyushu Okinawa Maternal and Child Health Study. BMC Pregnancy Childbirth 2014;14:79-90. Doi: 10.1186/1471-2393-14-79

20 Jaddoe VWV, Bakker R, Hofman A, et al. Moderate alcohol consumption during pregnancy and the risk of low birth weight and preterm birth. The generation R study. Ann Epidemiol 2007;17 (10):834-840. Doi: 10.1016/j.annepidem.2007.04.001

21 Lundsberg LS, Bracken MB, Saftlas AF. Low-to-moderate gestational alcohol use and intrauterine growth retardation, low birthweight, and preterm delivery. Ann Epidemiol 1997;7(07): 498-508. Doi: 10.1016/S1047-2797(97)00081-1

22 Mariscal M, Palma S, Llorca J, Pérez-Iglesias R, Pardo-Crespo R. Delgado-Rodríguez. Pattern of alcohol consumption during pregnancy and risk for low birthweight. Ann Epidemiol 2006; 6:432-438. Doi: 10.1016/j.annepidem.2005.07.058

23 Gorn S, Romero Mendonza M, Tiburcio Sainz M, Medina-Mora Icaza ME, Rojas Guiot E. Risgos associados al consumo de alohol durante el embarazo en mujeres alcohólicas de la Ciudad de México. Salud Ment 2007;30:31-38

24 Windham GC, Fenster L, Hopkins B, Swan SH. The association of moderate maternal and paternal alcohol consumption with birthweight and gestational age. Epidemiology 1995;6(06):591-597

25 Bada HS, Das A, Bauer CR, et al. Low birth weight and preterm births: etiologic fraction attributable to prenatal drug exposure. J Perinatol 2005;25(10):631-637. Doi: 10.1038/sj.jp.7211378

26 Olsen J, Pereira AdaC, Olsen SF. Does maternal tobacco smoking modify the effect of alcohol on fetal growth? Am J Public Health 1991;81(01):69-73

27 Borges G, Lopez-Cervantes M, Medina-Mora ME, Tapia-Conyer R, Garrido F. Alcohol consumption, low birth weight, and preterm delivery in the National Addiction Survey (Mexico). Int J Addict 1993;28(04):355-368

28 Brooke OG, Anderson HR, Bland JM, Peacock JL, Stewart CM. Effects on birth weight of smoking, alcohol, caffeine, socioeconomic factors, and psychosocial stress. BMJ 1989;298 (6676):795-801. Doi: 10.1136/bmj.298.6676.795

29 Nykjaer C, Alwan NA, Greenwood DC, et al. Maternal alcohol intake prior to and during pregnancy and risk of adverse birth outcomes: evidence from a British cohort. J Epidemiol Community Health 2014;68(06):542-549. Doi: 10.1136/jech-2013202934

30 Bird AL, Grant CC, Bandara DK, et al. Maternal health in pregnancy and associations with adverse birth outcomes: Evidence from Growing Up in New Zealand. Aust N Z J Obstet Gynaecol 2017;57 (01):16-24. Doi: 10.1111/ajo.12557

31 Virji SK. The relationship between alcohol consumption during pregnancy and infant birthweight. An epidemiologic study. Acta Obstet Gynecol Scand 1991;70(4-5):303-308. Doi: 10.3109/ 00016349109007877

32 Jackson DJ, Batiste E, Rendall-Mkosi K. Effect of smoking and alcohol use during pregnancy on the occurrence of low birthweight in a farming region in South Africa. Paediatr Perinat Epidemiol 2007;21(05):432-440. Doi: 10.1111/j.1365-3016. 2007.00847.x 
33 Lundsberg LS, Illuzzi JL, Belanger K, Triche EW, Bracken MB. Low-tomoderate prenatal alcohol consumption and the risk of selected birth outcomes: a prospective cohort study. Ann Epidemiol 2015;25 (01):46-54.e3. Doi: 10.1016/j.annepidem.2014.10.011

34 Witt WP, Mandell KC, Wisk LE, et al. Infant birthweight in the US: the role of preconception stressful life events and substance use. Arch Women Ment Health 2016;19(03):529-542. Doi: 10.1007/ s00737-015-0595-z

35 Marbury MC, Linn S, Monson R, Schoenbaum S, Stubblefield PG, Ryan KJ. The association of alcohol consumption with outcome of pregnancy. Am J Public Health 1983;73(10):1165-1168

36 Oster RT, Toth EL. Longitudinal rates and risk factors for adverse birth weight among first nations pregnancies in Alberta. J Obstet Gynaecol Can 2016;38(01):29-34. Doi: 10.1016/j.jogc.2015.10.011

37 Mills JL, Graubard BI, Harley EE, Rhoads GG, Berendes HW. Maternal alcohol consumption and birth weight. How much drinking during pregnancy is safe? JAMA 1984;252(14):1875-1879. Doi: 10.1001/jama.1984.03350140021018

38 Grisso JA, Roman E, Inskip H, Beral V, Donovan J. Alcohol consumption and outcome of pregnancy. J Epidemiol Community Health 1984;38(03):232-235. Doi: 10.1136/jech.38.3.232

39 Little RE, Asker RL, Sampson PD, Renwick JH. Fetal growth and moderate drinking in early pregnancy. Am J Epidemiol 1986;123 (02):270-278. Doi: 10.1093/oxfordjournals.aje.a114235

40 Day NL, Jasperse D, Richardson G, et al. Prenatal exposure to alcohol: effect on infant growth and morphologic characteristics. Pediatrics 1989;84(03):536-541

41 Passaro KT, Little RE, Savitz DA, Noss J; The ALSPAC Study Team. Avon Longitudinal Study of Pregnancy and Childhood. The effect of maternal drinking before conception and in early pregnancy on infant birthweight. Epidemiology 1996;7(04):377-383. Doi: 10.1097/00001648-199607000-00007

42 Ruijter I, Miller JM Jr. Evaluation of low birthweight in African Americans. J Natl Med Assoc 1999;91(12):663-667

43 Irner TB, Teasdale TW, Nielsen T, Vedal S, Olofsson M. Substance use during pregnancy and postnatal outcomes. J Addict Dis 2012; 31(01):19-28. Doi: 10.1080/10550887.2011.642765

44 Márquez RCM, Borroto KL, Ranero ABG. [Factors influencing low birthweight in the health area "Camilo Cienfuegos" Chambas, 2007-2008]Mediciego. 2011;17:1-7

45 Dičkutė J, Padaiga Z, Grabauskas V, Gaižauskienė A, Basys V, Obelenis V. [Do maternal social factors, health behavior and work conditions during pregnancy increase the risk of low birth weight in Lithuania?] Medicina (Kaunas) 2002;38(03):321-332

46 Silva Id, Quevedo LdeA, Silva RA, Oliveira SS, Pinheiro RT. Association between alcohol abuse during pregnancy and birth weight. Rev Saude Publica 2011;45(05):864-869. Doi: 10.1590/S003489102011005000062

47 Faden VB, Graubard BI, Dufour M. The relationship of drinking and birth outcome in a US national sample of expectant mothers. Paediatr Perinat Epidemiol 1997;11(02):167-180. Doi: 10.1046/ j.1365-3016.1997.d01-20.x

48 McDonald AD, Armstrong BG, Sloan M. Cigarette, alcohol, and coffee consumption and prematurity. Am J Public Health 1992;82 (01):87-90

49 Sbrana M, Grandi C, Brazan M, et al. Alcohol consumption during pregnancy and perinatal results: a cohort study. Sao Paulo Med J 2016;134(02):146-152. Doi: 10.1590/1516-3180.2015.02040211

50 Lumley J, Correy JF, Newman NM, Curran JT. Cigarette smoking, alcohol consumption and fetal outcome in Tasmania 1981-82. Aust N Z J Obstet Gynaecol 1985;25(01):33-40

51 Okah FA, Cai J, Hoff GL. Term-gestation low birth weight and health-compromising behaviors during pregnancy. Obstet Gynecol 2005;105(03):543-550. Doi: 10.1097/01.AOG.0000148267. 23099.b7

52 Maruoka K, Yagi M, Akazawa K, Kinukawa N, Ueda K, Nose Y. Risk factors for low birthweight in Japanese infants. Acta Paediatr 1998;87(03):304-309. Doi: 10.1111/j.1651-2227.1998.tb01442.x
53 Primatesta P, Del Corno G, Bonazzi MC, Waters WE. Alcohol and pregnancy: an international comparison.J Public Health Med 1993; 15(01):69-76. Doi: 10.1093/oxfordjournals.pubmed.a042822

54 Strutz KL, Richardson LJ, Hussey JM. Selected preconception health indicators and birth weight disparities in a national study. Womens Health Issues 2014;24(01):e89-e97. Doi: 10.1016/j. whi.2013.10.001

55 Li YM, Chang TK. Maternal demographic and psyhosocial factors associated with low birth weight in eastern Taiwan. Kaohsiung J Med Sci 2005;21(11):502-510. Doi: 10.1016/S1607-551X(09) 70158-5

56 Shu XO, Hatch MC, Mills J, Clemens J, Susser M. Maternal smoking, alcohol drinking, caffeine consumption, and fetal growth: results from a prospective study. Epidemiology 1995;6(02):115-120

57 Pfinder M, Kunst AE, Feldmann R, van Eijsden M, Vrijkotte TG. Preterm birth and small for gestational age in relation to alcohol consumption during pregnancy: stronger associations among vulnerable women? Results from two large Western-European studies. BMC Pregnancy Childbirth 2013;13:49. Doi: 10.1186/ 1471-2393-13-49

58 Gray R. Low-to-moderate alcohol consumption during pregnancy and child development-moving beyond observational studies. BJOG 2013;120(09):1039-1041. Doi: 10.1111/1471-0528.12211

59 Kesse E, Clavel-Chapelon F, Slimani N, van Liere M; E3N Group. Do eating habits differ according to alcohol consumption? Results of a study of the French cohort of the European Prospective Investigation into Cancer and Nutrition (E3NEPIC). Am J Clin Nutr 2001;74(03):322-327. Doi: 10.1093/ ajcn/74.3.322

60 Parazzini F, Chatenoud L, Surace M, et al. Moderate alcohol drinking and risk of preterm birth. Eur J Clin Nutr 2003;57(10): 1345-1349. Doi: 10.1038/sj.ejcn.1601690

61 Walpole I, Zubrick S, Pontré J. Is there a fetal effect with low to moderate alcohol use before or during pregnancy? J Epidemiol Community Health 1990;44(04):297-301. Doi: 10.1136/ jech.44.4.297

62 Helske S, Vuorela P, Carpén O, Hornig C, Weich H, Halmesmäki E. Expression of vascular endothelial growth factor receptors 1,2 and 3 in placentas from normal and complicated pregnancies. Mol Hum Reprod 2001;7(02):205-210. Doi: 10.1093/molehr/7.2.205

$63 \mathrm{Gu}$ JW, Elam J, Sartin A, Li W, Roach R, Adair TH. Moderate levels of ethanol induce expression of vascular endothelial growth factor and stimulate angiogenesis. Am J Physiol Regul Integr Comp Physiol 2001;281(01):R365-R372. Doi: 10.1152/ajpregu.2001. 281.1.R365

64 de Lorimier AA. Alcohol, wine, and health. Am J Surg 2000;180 (05):357-361. Doi: 10.1016/S0002-9610(00)00486-4

65 Kelly Y, Sacker A, Gray R, Kelly J, Wolke D, Quigley MA. Light drinking in pregnancy, a risk for behavioural problems and cognitive deficits at 3 years of age? Int J Epidemiol 2009;38 (01):129-140. Doi: 10.1093/ije/dyn230

66 Barr HM, Bookstein FL, O'Malley KD, Connor PD, Huggins JE, Streissguth AP. Binge drinking during pregnancy as a predictor of psychiatric disorders on the Structured Clinical Interview for DSM-IV in young adult offspring. Am J Psychiatry 2006;163(06): 1061-1065. Doi: 10.1176/ajp.2006.163.6.1061

67 Sood B, Delaney-Black V, Covington C, et al. Prenatal alcohol exposure and childhood behavior at age 6 to 7 years: I. doseresponse effect. Pediatrics 2001;108(02):E34

68 Jacobson JL, Jacobson SW, Sokol RJ, Martier SS, Ager JW, Shankaran S. Effects of alcohol use, smoking, and illicit drug use on fetal growth in black infants. J Pediatr 1994;124(5 Pt 1):757-764. Doi: 10.1016/S0022-3476(05)81371-X

69 Stroup DF, Berlin JA, Morton SC, et al. Meta-analysis of observational studies in epidemiology: a proposal for reporting. Metaanalysis Of Observational Studies in Epidemiology (MOOSE) group. JAMA 2000;283(15):2008-2012. Doi: 10.1001/jama. 283.15.2008 